
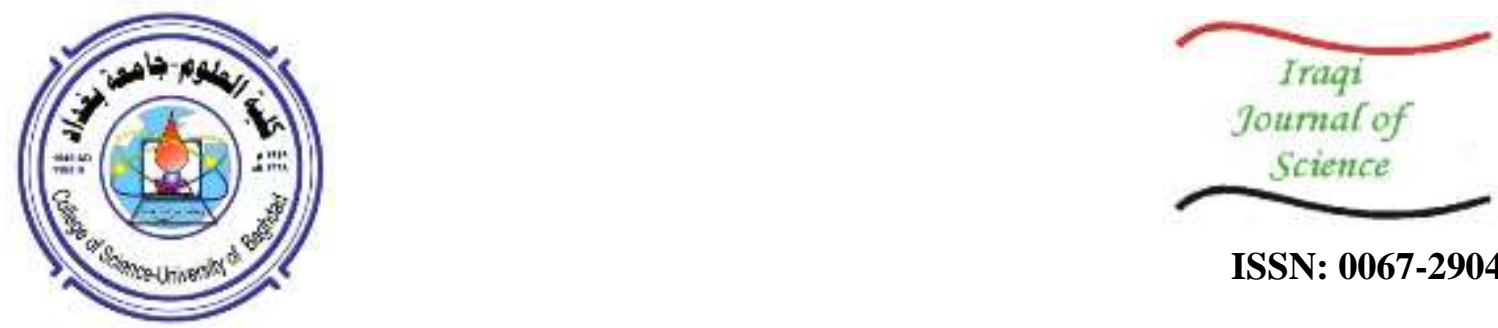

ISSN: 0067-2904

\title{
The Effect of Sodium Chloride on Ion Association of Lysine and Arginine Ionizable Side Chains Amino Acids with Dehydro-L-ascorbic Acid in Aqueous Solution at Different Temperatures
}

\author{
Muhammed J. Kadhim \\ Department of Power Mechanical Techniques, Institute of Technology - Baghdad, Middle Technical University, \\ Baghdad, Iraq.
}

\begin{abstract}
Molar conductance $(\Lambda)$ of ionizable side chains amino acids, lysine (Lys) and arginine (Arg) with dehydroascorbic acid (DHA) in water and in $\mathrm{NaCl}$ solutions was measured at temperatures range $298 \mathrm{~K}$ to $313 \mathrm{~K}$. The limited molar conductance $\left(\Lambda^{\circ}\right)$ and the constant of the ions association $\left(\mathrm{K}_{\mathrm{A}}\right)$ are calculated using the Shedlovsky techniques. The dynamic radius of the concerned ion $(\mathrm{R})$ is calculated by used Stokes-Einstein relation. The heat of association, the Gibbs free energy, the change of entropy and activation energy $\left(\Delta \mathrm{H}^{\circ} / \mathrm{kJ} \mathrm{mol}^{-1}, \Delta \mathrm{G}^{\mathrm{O}} / \mathrm{kJ} \mathrm{mol}^{-1}, \Delta \mathrm{S}^{\mathrm{O}} / \mathrm{J} \mathrm{K} \mathrm{K}^{-1}\right.$ $\mathrm{mol}^{-1}$, and $\Delta \mathrm{E}_{\mathrm{S}} / \mathrm{kJ} \mathrm{mol}^{-1}$ ) respectively), also calculated. The data show increases the molar conductance with increase in temperature and decreasing in values at addition of DHA to Lys and Arg solutions. The association ions in $\mathrm{NaCl}$ solutions appear to increase in radius and decrease in diffusion coefficient relative to water solutions. $\Delta \mathrm{E}_{\mathrm{S}}$, shows in most samples a positive value for the association and the values in $\mathrm{NaCl}$ solutions has lower relative to the water solutions. $\Delta \mathrm{G}^{\mathrm{o}}$ is a trend to decrease with an increase in DHA concentration in water and $\mathrm{NaCl}$ solutions. The ion association is exothermic reaction relative to the negative value of $\Delta \mathrm{H}^{\circ}$. The $\Delta \mathrm{S}^{\circ}$ and $\Delta \mathrm{H}^{\circ}$ results, for Lys and Arg solutions, show decreasing in values at increase in DHA concentration in water and $\mathrm{NaCl}$ solutions. $\Delta \mathrm{G}^{\mathrm{o}}\left(\mathrm{kJ} \mathrm{mol}^{-1}\right), \Delta \mathrm{S}^{\mathrm{o}}\left(\mathrm{J} \mathrm{K}^{-1} \mathrm{~mol}^{-1}\right)$, $\Delta \mathrm{H}^{\mathrm{o}}\left(\mathrm{kJ} \mathrm{mol}^{-1}\right)$, and $\Delta \mathrm{E}_{\mathrm{s}}\left(\mathrm{kJ} \mathrm{mol}^{-1}\right)$
\end{abstract}

Keywords: Amino acids, ascorbic acid, dehydroascorbic acid, conductance measurements.

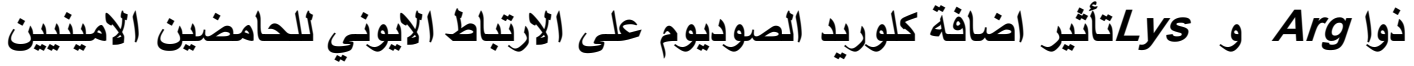 \\ المجاميع الجانبية المتأينة مع حامض الايهادروسكوربيك في المحلول المائي عند درجات حرارة مختلفة

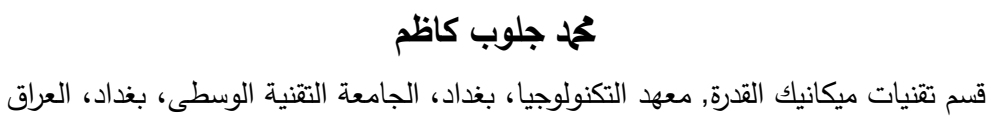

الخلاصة

تم قياس التوصيلية المولارية للحامضين الامينيين Lys و Arg ذوا الجاميع الجانبية المتأينة مع

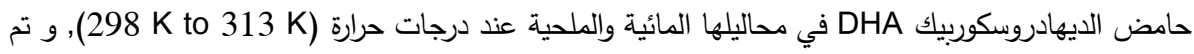

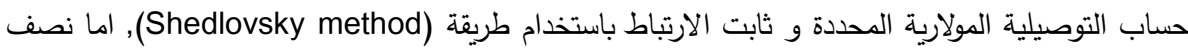

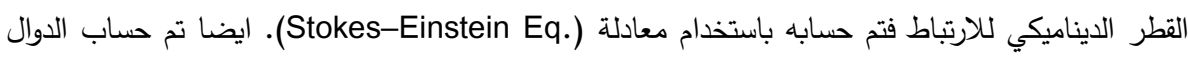

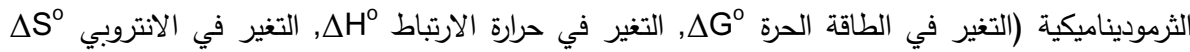

*Email: Muhammedkadhim74@gmail.com 


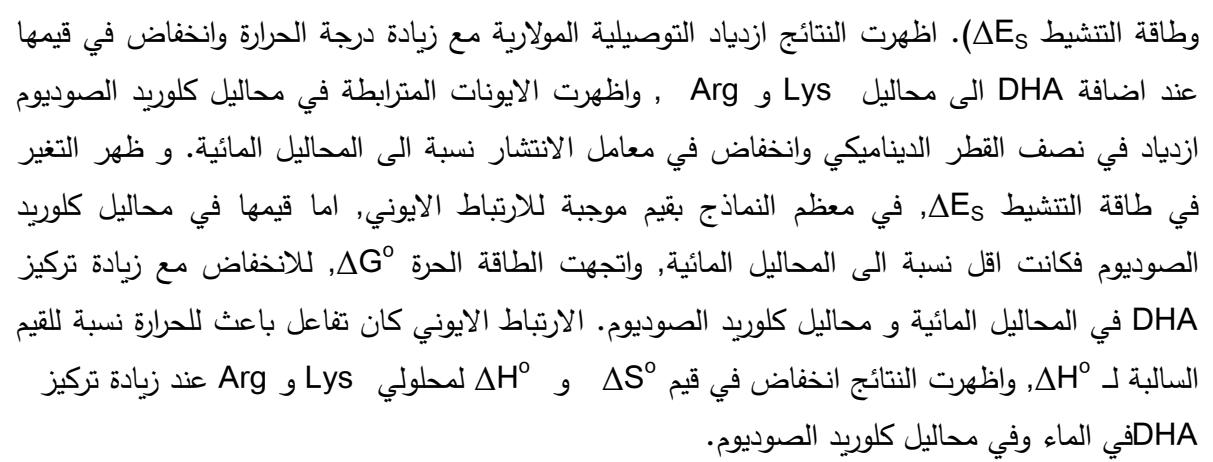

\section{Introduction}

Amino acids (AAs) are the main components of food. AAs represent the principle building blocks required for biosynthesis of protein [1]. In another side, vitamin $\mathrm{C}$ is contributing to various cellular functions and essential as an antioxidant [2].

Ascorbic acid (AA) and dehydroascorbic acid (DHA) are the chemical material source forms of vitamin C. The human diet is abundant by AA and DHA [3]. DHA is made from AA in the gastrointestinal tract lumen (GIL). The GIL is the basic site for absorption of AA and DHA. In addition to that, DHA is formed when an oxidants reacts with AA in the GIL [4]. DHA (Figure-1) is different from AA in hydrophilic property, because it is present in a deprotonated form. So, it can easily transfer through the membranes of the cell, and interacted by alkali compounds (e.g. to oxalic acid and threonic acid) [5]. In the human body, both DHA and AA have iterative antivirals biological activity but DHA also has neuroprotective effects. Nowadays DHA is organized as an investigations drug with no recognized indications. Both AAs and vitamin $\mathrm{C}$ are water-soluble, and they are coexistence in some metabolic reactions, medication, and food. In addition to that vitamin $\mathrm{C}$ improves an effect on increasing AAs absorption from the oral given dose [6].

Life on earth stands on water, hydrophobic interactions and hydrogen bonds (HB). HB has a central role in numerous biological processes. HB effects on transport of the membrane, drugs distribution in the biological environment and other different contributions [7]. Applications of HB in drug design are currently taking an interest [8]. Therefore, information about ion association of the interactions between DHA and amino acids as HB is very important since searching the interaction between drugs can help us to have them in a normal use [9], and because the interaction of AAs with DHA play an important role in biochemical environment. Many searches study the ion association between amino acids and different biological molecules [10-12], Since searching in ion association is key to knowledge the intermolecular interactions, structure-function relationships and structural biology. It is also assist in drugs design that binds with targets selectively.

This search reports the conductance measurements, the dynamic radiuses of the concerned ions, ion association constant and thermodynamic properties for DHA acid association with some ionizable side chains $\alpha$-AAs (Lysine, Lys and Arginine, Arg) in water solution and sodium chloride solutions in the range $298-313 \mathrm{~K}$ of temperatures.

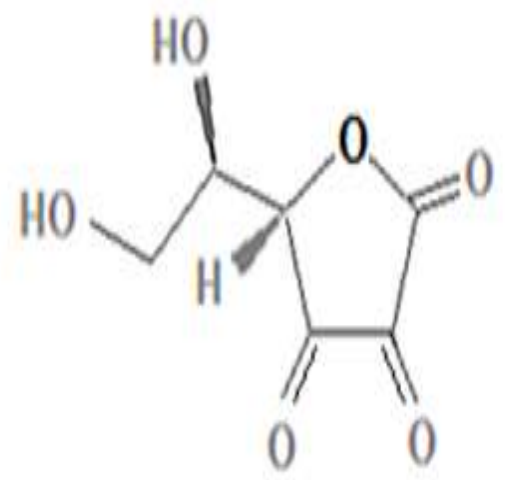

Figure 1-Dehydro-L-ascorbic acid (DHA).

\section{Materials and methods}

Lysine (Lys), arginine hydrochloride (Arg) (an ionazible- $\alpha$-amino acid) and ascorbic acid (AA), were obtained from BDH company with a purity proximate to $99.9 \%$. Deionized water used in all 
solutions has specific conductance, in the range of $(3-4 \mu \mathrm{S} / \mathrm{cm})$. The specific conductivity, $\kappa(\mu \mathrm{S} / \mathrm{cm})$, was measured by digital conductivity bridge (with a dip type immersion conductivity cell). All the solutions of lysine, arginine hydrochloride amino acids and dehydroascorbic acid were prepared at different concentrations $\left(2-5 \times 10^{-3} \mathrm{~mol} / \mathrm{L}\right)$ by dissolving the required amount of the sample in distilled deionized water. A thermostat water bath (GFL/D30938) device was used through conductivity measurements in the range of temperature $(298-313 \mathrm{~K})$. The measurements of weights using in preparation of solutions were complete by using a digital electrical balance (Sartorius RC 210D). All measurements had done at least in triplicates. A method used for preparation of DHA, carry out as follows:

"Ten grams of ascorbic acid is dissolved in $300 \mathrm{ml}$ of solvent, and $15 \mathrm{~g}$ of activated charcoal is added. Oxygen or air is bubbled through the solution at a flow rate of $20 \mathrm{ml} / \mathrm{min}$ for 30-60 $\mathrm{min}$ while the solution is gently stirred with a magnetic stirrer. At the completion of the reaction the solution is filtered [13]".

The oxidation reaction of AA to DHA in the presence of activated charcoal as a catalyst can be seen in equation represented by (Figure-2). The concentration of DHA in a solution determined by 2:6-dichlorophenolindophenol titrimetric analysis method [14].
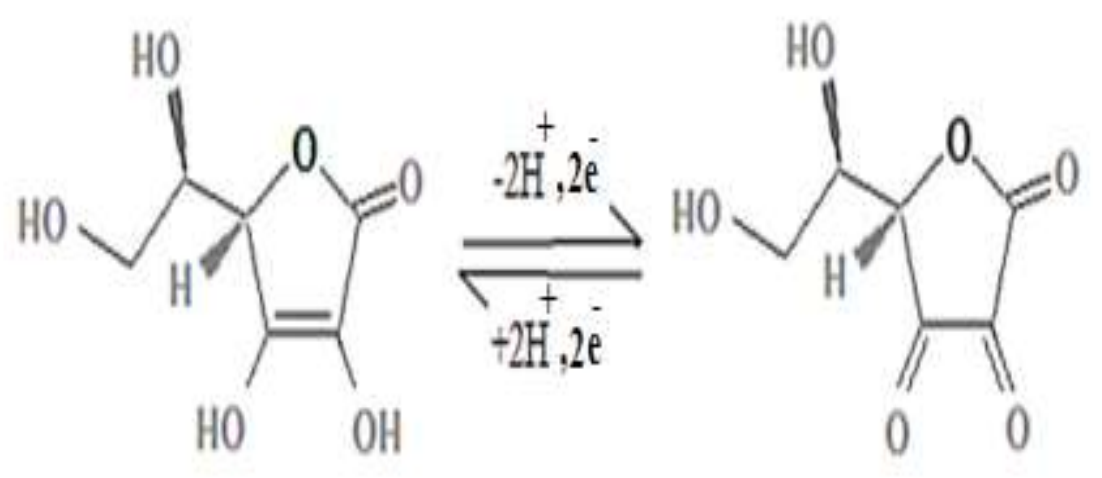

\section{Results and discussion}

Figure 2-Schematic illustration the oxidation reaction equation of AA to DHA.

\subsection{Association constants.}

Lysine (Lys) and arginine (Arg) amino acids have a polar ionizable side chains that can participate in hydrophobic interaction or hydrogen bonding to water, and to other AAs [15]. In other side DHA can accept a multiple HBs.

The predominate state of Lys and Arg in neutral solution can be shown in (Figure-3).

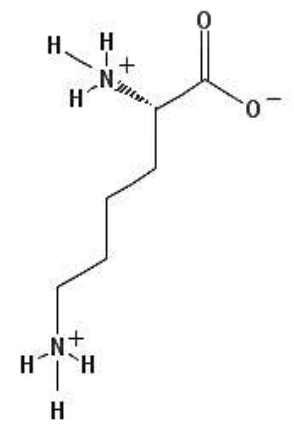

A

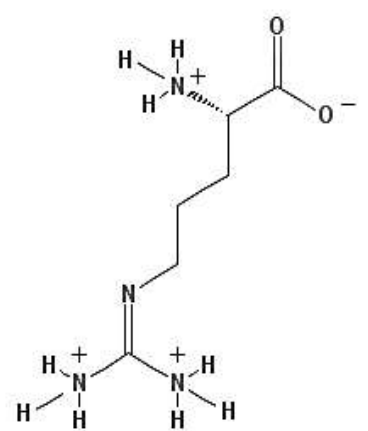

B

Figure 3-L- $\alpha$-amino acid: A-lysine, B-arginine

The conductance and viscosity as transport properties of solutions are important because itprovides values as useful information about ionic association. Understanding these properties provides a fundamental to the investigation of hydrogen bonding in the biological and chemical environment $[16]$. 
The physical properties of water used in the preparation of solutions are given in Table- 1 as reported in searches $[17,18]$.

Table-1: Densities, $\rho^{0}$, viscosities, $\eta$, and dielectric constant, $D$, of deionized water at different temperatures.

\begin{tabular}{cccc}
\hline$T / K$ & $\rho_{0} / \mathbf{g ~ m}^{-3}$ & $\boldsymbol{\eta} / \mathbf{g}^{-1} \mathbf{s}^{-1}$ & $D$ \\
\hline 298 & 0.9971 & 0.8903 & 78.30 \\
303 & 0.9957 & 0.7974 & 76.55 \\
308 & 0.9941 & 0.7194 & 74.83 \\
313 & 0.9923 & 0.6531 & 73.15 \\
\hline
\end{tabular}

The conductance values of ionic substances in dilute solutions with a wide range of temperature allow the determination of thermodynamic and association constants [19]. HBs increase in solution as a result to increase in the molar concentration. So the conductivity values analyzed at $\left(2-5 \times 10^{-3} \mathrm{M}\right)$ for DHA to $\left(2 \times 10^{-3} \mathrm{M}\right)$ of lysine and arginine amino acids in water and in $\left(2 \times 10^{-3} \mathrm{M}\right) \mathrm{NaCl}$ solutions. The solubility of AAs in water is very variable. So amino acids are affected at addition of inorganic salt by increase the solubility of AAs in a solution and this effect on transport properties of solutions [20].

Association constant $\mathrm{K}_{\mathrm{A}}$ is valued by uses a numerous of equations. Shedlovsky Equation 1 [21], is used to calculate $\mathrm{K}_{\mathrm{A}}$.

$$
\frac{1}{\Lambda S(Z)}=\frac{1}{\Lambda^{\circ}}+\frac{K_{A} C \Lambda f_{+}^{2} S(Z)}{\Lambda^{0^{2}}}
$$

Where $\Lambda\left(\mathrm{S} \mathrm{cm}^{2} \mathrm{~mol}^{-1}\right)$, is the molar conductivity, $\mathrm{C}\left(\mathrm{mol} \mathrm{dm}{ }^{-3}\right)$, the solution concentration, $\Lambda^{\circ}(\mathrm{S}$ $\left.\mathrm{cm}^{2} \mathrm{~mol}^{-1}\right)$, the limited molar conductance, $\mathrm{K}_{\mathrm{A}}\left(\mathrm{dm}^{3} \mathrm{~mol}^{-1}\right)$, the constant of ion association, $\mathrm{f}_{ \pm}$, and $\mathrm{S}(\mathrm{Z})$ are coefficient factors.

$\Lambda, \mathrm{f}_{ \pm}$, and $\mathrm{S}(\mathrm{Z})$ are calculated using Equations 2-4:

$$
\begin{gathered}
\Lambda=\frac{1000 \mathrm{~K}}{c} \\
-\log f_{ \pm}=\frac{A \sqrt{I}}{1+B R \sqrt{I}} \times 10^{6} \\
A=\frac{1.8247 \times 1)^{3 / 2}}{(D T} \quad B=\frac{0.5209 \times 10^{10}}{\sqrt{D T}} 3 \\
S(Z)=\left(\frac{z}{2}+\sqrt{1+\left(\frac{Z}{2}\right)^{2}}\right)^{2} \\
Z=\left[\frac{S}{\Lambda_{o}^{3 / 2}}\right] \sqrt{C \Lambda} ; \quad S=\alpha \Lambda_{o}+\beta ; \quad \beta=\frac{82.501}{\eta \sqrt{D T}} ; \quad \alpha=\frac{0.8204 \times 10^{6}}{(D T)^{3 / 2}}
\end{gathered}
$$

Where: $\mathrm{R}(\mathrm{m})$, is the dynamic radius for ion association, $\kappa\left(\mu \mathrm{S} \mathrm{m}^{-1}\right)$, is the specific conductivity, $\mathrm{D}$, is the dielectric constant, $\mathrm{C}\left(\mathrm{mol} \mathrm{dm}{ }^{-3}\right)$, is molar concentration, $\eta\left(\mathrm{g} \mathrm{m}^{-1} \mathrm{~s}^{-1}\right)$, is the viscosity, and $\mathrm{T}$ $(\mathrm{K})$, is the absolute temperature.

In the case of $S(Z)$, the degree of dissociation $\gamma$, can be calculated using equation 5: 


$$
\gamma=\frac{\Lambda S(Z)}{\Lambda^{0}}
$$

The value obtained from Equation 1, compared with Fuoss-Kraus equation, Equation 6 [22], and the result is very closer.

The dynamic radius of the concerned ion (Association distance) $\mathrm{R}$, for diffusing species can result with using Stokes-Einstein equation, Equation 7 [23].

$$
R_{ \pm}=\frac{k T}{6 \pi \eta D}
$$

Where $\mathrm{D}\left(\mathrm{m}^{2} \mathrm{~s}^{-1}\right)$, is the diffusion coefficient, $\mathrm{k}\left(\mathrm{J} \mathrm{K}^{-1}\right)$, is the Boltzmann constant, $\mathrm{T}(\mathrm{K})$, is the absolute temperature, and $\eta\left(\mathrm{kg} \mathrm{m}^{-1} \mathrm{~s}^{-1}\right)$, is the dynamic viscosity.

In this search, it is used the $\eta$, values based on the viscosity of water as listed in Table-1.

"Both diffusion and conductance involve the movement of ions, and as such, a connection between them exists. At infinite dilution, where interionic forces vanish, we may attribute to any given ion a characteristic drag, proportional to velocity, which resists motion through the solvent" [24]. So the diffusion coefficient values of diffusing species can be given by Einstein - Smoluchowski, Equation 8 [25].

$$
D=\mu K_{B} T
$$

Where, $\mu\left(\mathrm{m}^{2} \mathrm{~V}^{-1} \mathrm{~s}^{-1}\right)$, is the ionic mobility at infinitive dilution, $\mathrm{k}_{\mathrm{B}}\left(\mathrm{eV} \mathrm{K}^{-1}\right)$, is the Boltzmann constant, and $\mathrm{T}(\mathrm{K})$, is the absolute temperature.

Since, $\mu$, can be calculated according to Equation 9 [26].

$$
\mu=\frac{\lambda}{z F}
$$

Where: $\lambda\left(\mathrm{S} \mathrm{cm}^{2} \mathrm{~mol}^{-1}\right)$, is the ionic molar conductivity, $\mathrm{z}$, is the charge of ion and $\mathrm{F}$ (Coulomb $\mathrm{mol}^{-1}$ ), is Faraday constant.

The diffusion coefficient results from Einstein-Smoluchowski relation and the dynamic radius of the diffusing species $R_{ \pm}$, products from Stokes-Einstein equation calculation is shown in Table-2.

Table-2: Values of diffusion coefficients, $\mathrm{D} / 10^{-9} \mathrm{~m}^{2} / \mathrm{s}$, and the dynamic radius of the diffusing species, $\mathrm{R} / 10^{-10} \mathrm{~m}$, of Lysine and Arginine amino acids in water and in $2 \times 10^{-3} \mathrm{M} \mathrm{NaCl}$.

\begin{tabular}{|l|c|c|c|c|c|c|c|c|}
\hline \multicolumn{1}{|c|}{ T/K } & \multicolumn{2}{c|}{$\mathbf{2 9 8}$} & \multicolumn{2}{c|}{$\mathbf{3 0 3}$} & \multicolumn{2}{c|}{$\mathbf{3 0 8}$} & \multicolumn{2}{c|}{$\mathbf{3 1 3}$} \\
\hline Diffusing species & $\mathrm{D}$ & $\mathrm{R}$ & $\mathrm{D}$ & $\mathrm{R}$ & $\mathrm{D}$ & $\mathrm{R}$ & $\mathrm{D}$ & $\mathrm{R}$ \\
\hline $\mathrm{Arg} /$ water & 0.187 & 13.20 & 0.194 & 14.51 & 0.195 & 16.31 & 0.199 & 17.97 \\
\hline Arg/NaC1 & 0.115 & 21.39 & 0.118 & 23.86 & 0.121 & 26.28 & 0.125 & 28.62 \\
\hline Arg-DHA/water & 0.164 & 15.00 & 0.168 & 16.80 & 0.172 & 18.50 & 0.176 & 20.32 \\
\hline Arg-DHA/NaC1 & 0.103 & 23.88 & 0.105 & 26.81 & 0.108 & 29.44 & 0.111 & 23.23 \\
\hline Lys/water & 0.249 & 09.88 & 0.254 & 11.10 & 0.260 & 12.23 & 0.265 & 13.50 \\
\hline Lys/NaC1 & 0.146 & 16.85 & 0.150 & 18.77 & 0.153 & 20.78 & 0.157 & 22.78 \\
\hline Lys-DHA/water & 0.236 & 10.42 & 0.241 & 11.68 & 0.246 & 12.93 & 0.251 & 14.25 \\
\hline Lys-DHA/NaC1 & 0.154 & 15.97 & 0.157 & 17.93 & 0.161 & 19.75 & 0.165 & 21.68 \\
\hline
\end{tabular}

As shown in (Figure-1) DHA is a neutral molecule and the molar conductivity closer to zero while Lys and Arg amino acid at neutral $\mathrm{pH}$ (Figure-3) contains more than one of a positive $\alpha$-ammonium group, so the molar conductivity is higher. And as a reason we take the conductivity of Lys and Arg solution to comparative with the conductivity of ion association between Lys-DHA, and Arg-DHA in water and $\mathrm{NaCl}$ solutions.

The molar conductivity, $\Lambda$, and the association constant $\mathrm{K}_{\mathrm{A}}$ (Calculated by using Eq.1), of ion association in water and in $\mathrm{NaCl}$ solutions at different temperature are listed in Table-3. 
Table 3-The molar conductivity, $\Lambda / \mathrm{S} \mathrm{cm}^{2} \mathrm{~mol}^{-1}$, the association constant, $\mathrm{K}_{\mathrm{A}} / \mathrm{dm}^{3} \mathrm{~mol}^{-1}$ and the limiting molar conductivity, $\Lambda^{\circ} / \mathrm{S} \mathrm{cm}^{2} \mathrm{~mol}^{-1}$, of different solutions at different temperature relative to DHA concentration.

\begin{tabular}{|c|c|c|c|c|c|c|c|c|}
\hline \multicolumn{9}{|c|}{$T / K$} \\
\hline DHA & \multicolumn{2}{|c|}{298} & \multicolumn{2}{|c|}{303} & \multicolumn{2}{|c|}{308} & \multicolumn{2}{|c|}{313} \\
\hline $\mathrm{C} \times 10^{-3} \mathrm{M}$ & $\bar{\Lambda}$ & $\mathbf{K}_{\mathrm{A}}$ & $\boldsymbol{\Lambda}$ & $\mathbf{K}_{\mathrm{A}}$ & $\bar{\Delta}$ & $\mathbf{K}_{\mathbf{A}}$ & $\mathbf{A}$ & $\mathbf{K}_{\mathrm{A}}$ \\
\hline \multicolumn{9}{|c|}{ Lys $\left(2 \times 10^{-3} \mathrm{M}\right) /$ water } \\
\hline $\mathbf{0}$ & 133 & - & 137 & - & 141 & - & 147 & \\
\hline 2 & 107 & 1236 & 110 & 1170 & 114 & 1094 & 120 & 0988 \\
\hline 3 & 073 & 2259 & 077 & 2022 & 080 & 1897 & 085 & 1698 \\
\hline 4 & 061 & 2612 & 065 & 2293 & 069 & 2048 & 075 & 1742 \\
\hline 5 & 043 & 4652 & 046 & 4079 & 050 & 3478 & 055 & 2908 \\
\hline$\Lambda^{0}$ & \multicolumn{2}{|c|}{230} & \multicolumn{2}{|c|}{232} & \multicolumn{2}{|c|}{235} & \multicolumn{2}{|c|}{239} \\
\hline \multicolumn{9}{|c|}{ Lys $\left(2 \times 10^{-3} \mathrm{M}\right) / \mathrm{NaCl}$} \\
\hline $\mathbf{0}$ & 235 & - & 238 & - & 242 & - & 247 & - \\
\hline 2 & 206 & 1059 & 209 & 1029 & 214 & 0986 & 219 & 0953 \\
\hline 3 & 134 & 2230 & 137 & 2136 & 141 & 2036 & 146 & 1921 \\
\hline 4 & 105 & 3000 & 108 & 2840 & 112 & 2666 & 118 & 2422 \\
\hline 5 & 082 & 4223 & 086 & 3834 & 090 & 3534 & 096 & 3133 \\
\hline $\mathbf{\Delta}^{\circ}$ & \multicolumn{2}{|c|}{420} & \multicolumn{2}{|c|}{422} & \multicolumn{2}{|c|}{426} & \multicolumn{2}{|c|}{431} \\
\hline \multicolumn{9}{|c|}{$\operatorname{Arg}\left(2 \times 10^{-3} \mathrm{M}\right) /$ water } \\
\hline $\begin{array}{lll}0 \\
\end{array}$ & 095 & - & 098 & - & 102 & - & 107 & - \\
\hline 2 & 068 & 1090 & 071 & 1021 & 075 & 0980 & 081 & 0874 \\
\hline 3 & 047 & 1965 & 051 & 1686 & 055 & 1543 & 060 & 1363 \\
\hline 4 & 034 & 3209 & 037 & 2768 & 041 & 2393 & 047 & 1895 \\
\hline 5 & 027 & 4340 & 030 & 3591 & 034 & 2965 & 040 & 2228 \\
\hline$\Lambda^{\circ}$ & \multicolumn{2}{|c|}{140} & \multicolumn{2}{|c|}{$\frac{1}{143}$} & \multicolumn{2}{|c|}{149} & \multicolumn{2}{|c|}{155} \\
\hline \multicolumn{9}{|c|}{$\operatorname{Arg}\left(2 \times 10^{-3} \mathrm{M}\right) / \mathrm{NaCl}$} \\
\hline $\begin{array}{lll}0 \\
0\end{array}$ & 195 & - & 198 & - & 202 & - & 208 & - \\
\hline 2 & 177 & 1069 & 181 & 1016 & 185 & 0992 & 191 & 0946 \\
\hline 3 & 118 & 2115 & 121 & 2014 & 124 & 1960 & 130 & 1812 \\
\hline 4 & 089 & 3119 & 092 & 2924 & 096 & 2733 & 102 & 2460 \\
\hline 5 & 069 & 4456 & 072 & 4228 & 075 & 3857 & 080 & 3457 \\
\hline$\Lambda^{\circ}$ & \multicolumn{2}{|c|}{362} & \multicolumn{2}{|c|}{364} & \multicolumn{2}{|c|}{369} & \multicolumn{2}{|c|}{375} \\
\hline
\end{tabular}

The limiting molar conductivity, as an approximation, is related to the molar conductance and the molar concentration $(\mathrm{C})$ square root by [27]:

$$
\Lambda=\Lambda^{\circ}-A \sqrt{C}
$$

Where, $\mathrm{A}$ is a constant. The plot of this relation can be seen in the Figures- $(4,5)$ below.
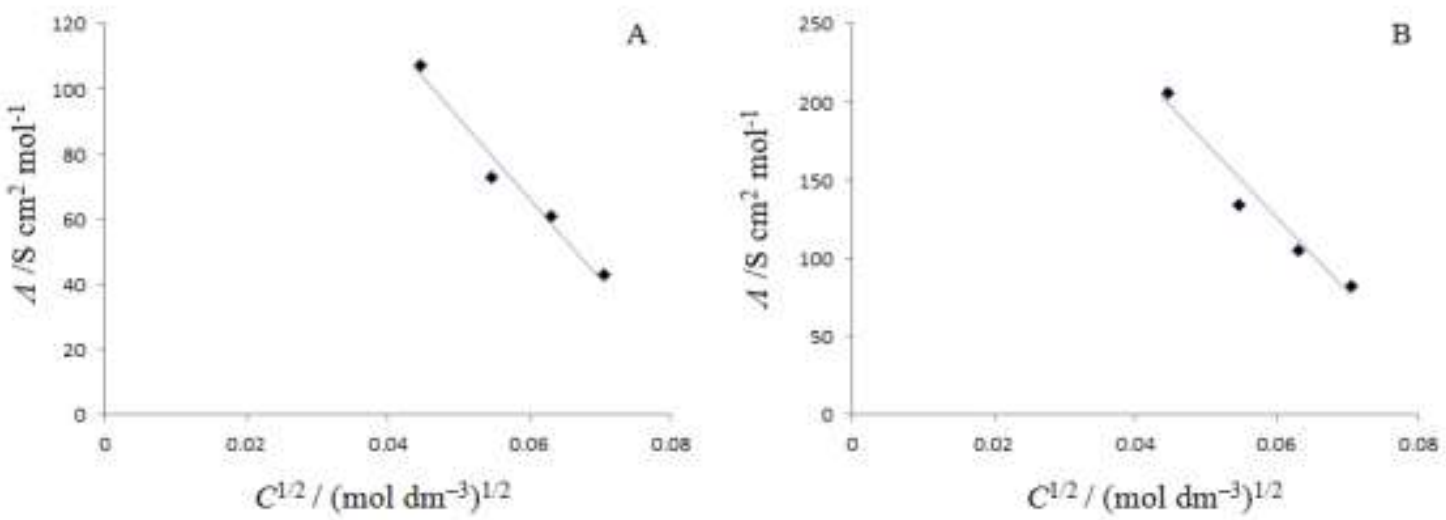

Figure 4-The dependence of $\Lambda\left(\mathrm{S} \mathrm{cm}^{2} \mathrm{~mol}^{-1}\right)$, on $\mathrm{C}^{1 / 2}\left(\mathrm{~mol} \mathrm{dm}^{-3}\right)^{1 / 2}$, of Lys: DHA, A- in water, B- in $\mathrm{NaCl}$ solutions at $298 \mathrm{~K}$. 

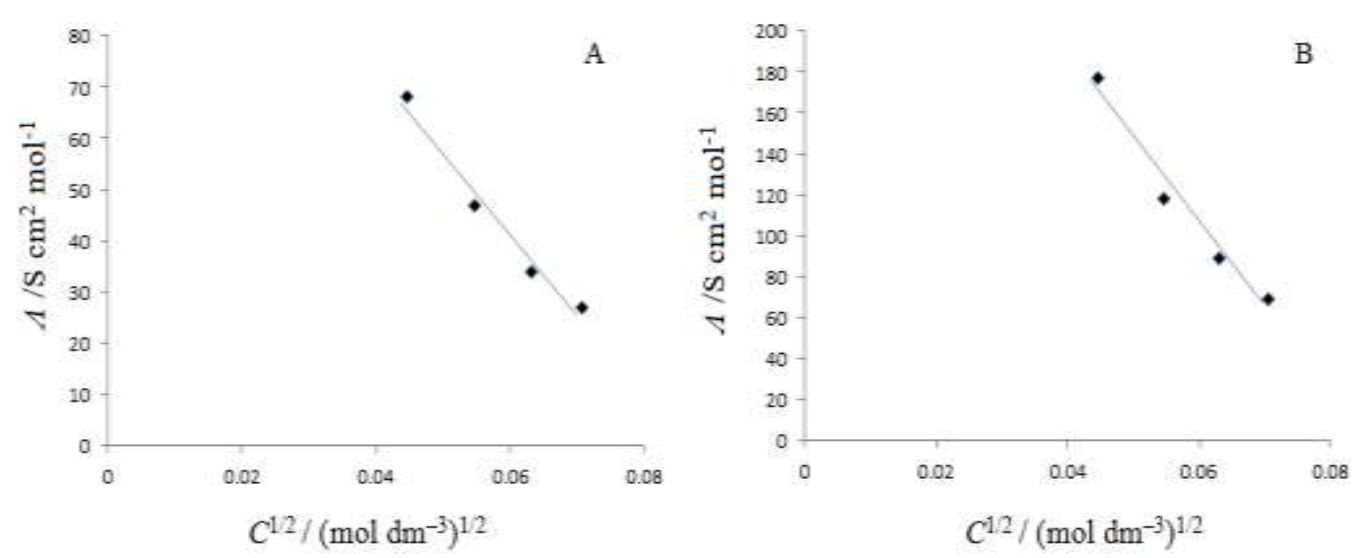

Figure 5-The dependence of $\Lambda\left(\mathrm{S} \mathrm{cm}^{2} \mathrm{~mol}^{-1}\right)$, on $\left.\mathrm{C}^{1 / 2}(\mathrm{~mol} \mathrm{dm})^{-3}\right)^{1 / 2}$, of Arg: DHA, A- in water, B- in $\mathrm{NaCl}$ solutions at $298 \mathrm{~K}$.

The molar conductivity of Lys and Arg appear decreasing in values at the addition of DHATable-3, and the values more decreasing at increase DHA concentration in dilute solutions. And this accustomed to those substances which have more probability for multiple hydrogen bonds display lower conductance relative to substances don't have or less probability. The limited molar conductance showed increasing in values at increase temperature and decreasing in values for association constant $\mathrm{K}_{\mathrm{A}}$. The reason is due to the decrease of solution viscosity, and increase in the mobility of ions or condensed extent of ion solvation in solutions. The increase in thermal energy as a result lead to more bond breaking, so the ions have more mobility and frequency [28]. Table-2 showed that the dynamic radiuses of the concerned ions increase as diffusion of the ions increase related to change in temperature, and the $\mathrm{R}$ of $\mathrm{AAs}$ in $\mathrm{NaCl}$ solutions haveincreased in size and decrease in diffusion coefficient and this accustomed to increase AAs solubility as compared with the same solutions in water.

3.2 Thermodynamic functions.

The chemical and physical properties of HB in solutions redirect the comprehensive intermolecular changes as a result of formation of $\mathrm{HB}$.

HB not only effects on the dynamic properties but also the thermodynamic properties of solutions because of the frequent break and reformation of HBs [16]. HB is abundant in solutions. It is found in the main biological and chemical processes. HBs as strength take a site between the covalent bond and van der Waals interaction. So this strength of HB takes a range of energies that permits fast dissociation and association under ambient conditions. Like fast HB dynamics are essential in a wideranging of systems, so it can acknowledgment the properties of water and biological solutions [29]. The activation energy $\left(\Delta \mathrm{E}_{S}\right)$, which is mean as the accessible energy size for an interaction to come to pass in a chemical environment is calculated from $S$. A. Arrhenius equation [28]. So the $-\Delta E_{S} / 2.303 R$ value is related to the $\log \Lambda$ and $1 / \mathrm{T}$ through Equation 11.

$$
\log \Lambda=-\left(\frac{\Delta E_{s}}{2.303 R}\right)\left(\frac{1}{T}\right)+\log A
$$

Where: A, Arrhenius factor, $\mathrm{T}(\mathrm{K})$, is the absolute temperature, $\mathrm{R}\left(\mathrm{J} \mathrm{K}^{-1} \mathrm{~mol}^{-1}\right)$, is the universal gas constant, $\Delta \mathrm{E}_{\mathrm{S}}\left(\mathrm{kJ} \mathrm{mol}^{-1}\right)$, Arrhenius activation energy, and $\Lambda\left(\mathrm{S} \mathrm{cm}^{2} \mathrm{~mol}^{-1}\right)$, is the molar conductance. The plot of this relation can be seen in the Figures- $(6,7)$ below. 

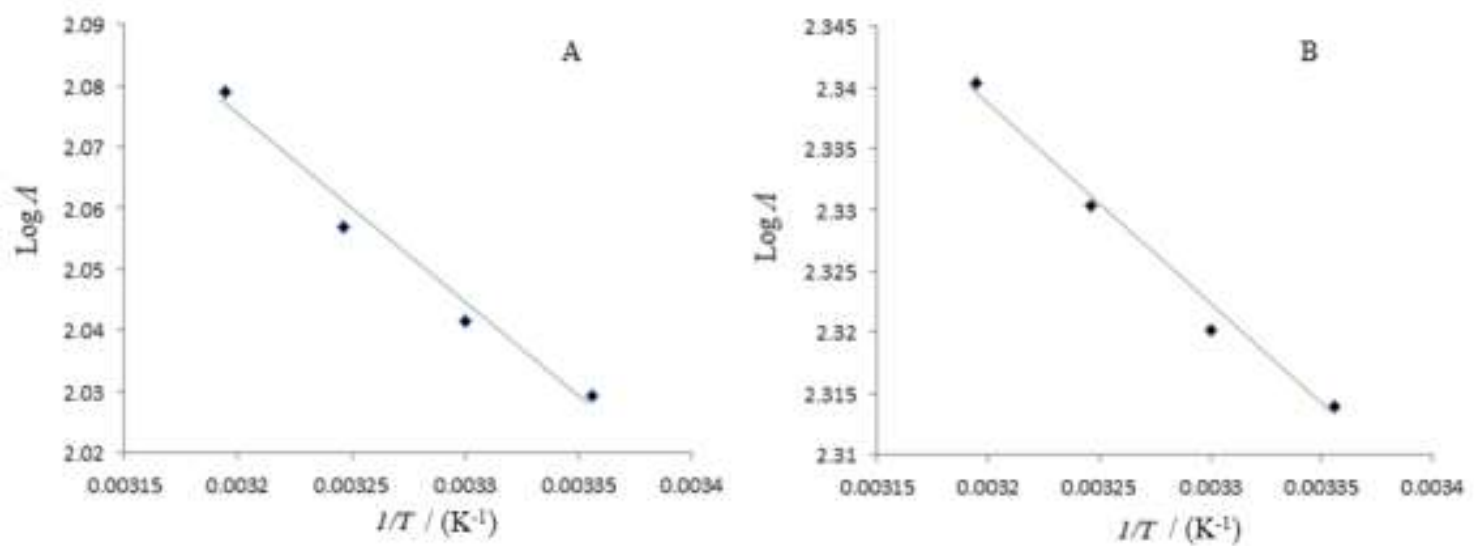

Figure 6-The linear relationship between $\log \Lambda$ and 1/T $\left(\mathrm{K}^{-1}\right)$, for Lys: DHA, A- in water and B- in $\mathrm{NaCl}$ solutions.
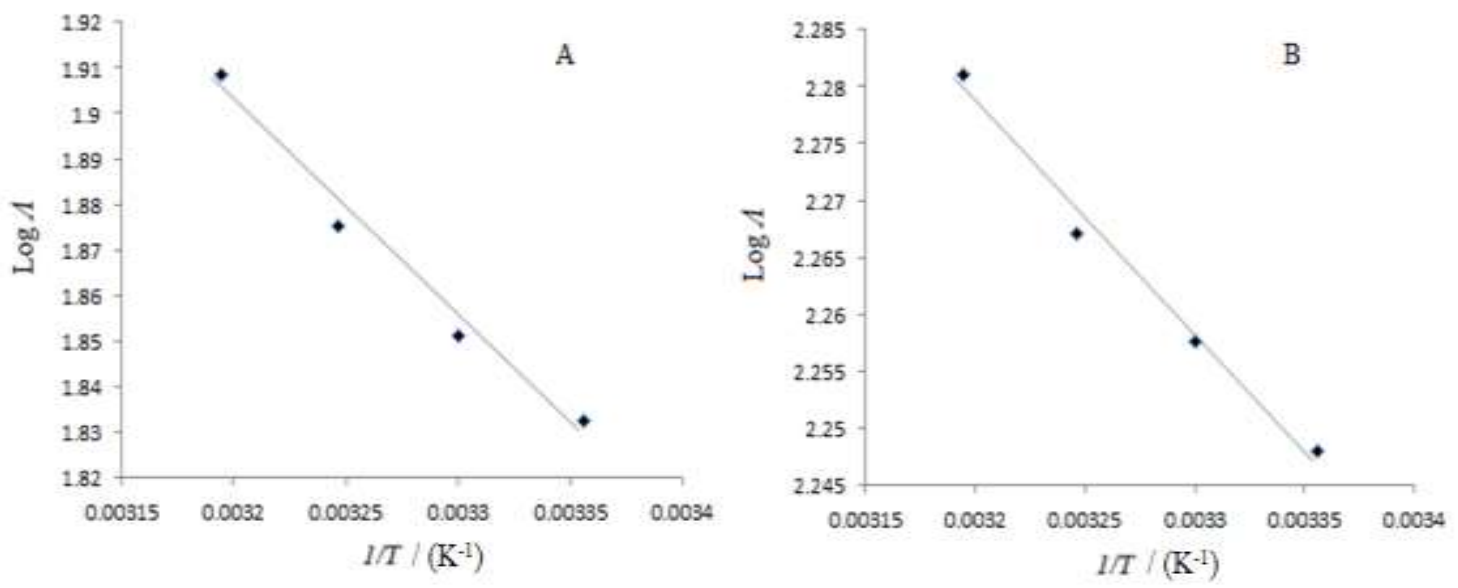

Figure 7-The linear relationship between $\log \Lambda$ and $1 / \mathrm{T}\left(\mathrm{K}^{-1}\right)$, for Arg: DHA, A- in water and B- in $\mathrm{NaCl}$ solutions.

The association enthalpy $\Delta \mathrm{H}^{\mathrm{o}}\left(\mathrm{kJ} \mathrm{mol}^{-1}\right)$, represents the association heat change when one mole of a compound result from elements and calculated by used Van't Hoff's expression [28]. So the $-\Delta \mathrm{H}^{\circ} / 2.303 \mathrm{R}$ value is related to the $\log \mathrm{K}_{\mathrm{A}}$ and $1 / \mathrm{T}$ through relation 12 .

$$
\log K_{A}=-\left(\frac{\Delta H^{\circ}}{2.303 R}\right)\left(\frac{1}{T}\right)+\left(\frac{\Delta S^{\circ}}{2.303 R}\right)
$$

The plot of this relation can be seen in Figures- $(8,9)$ below.
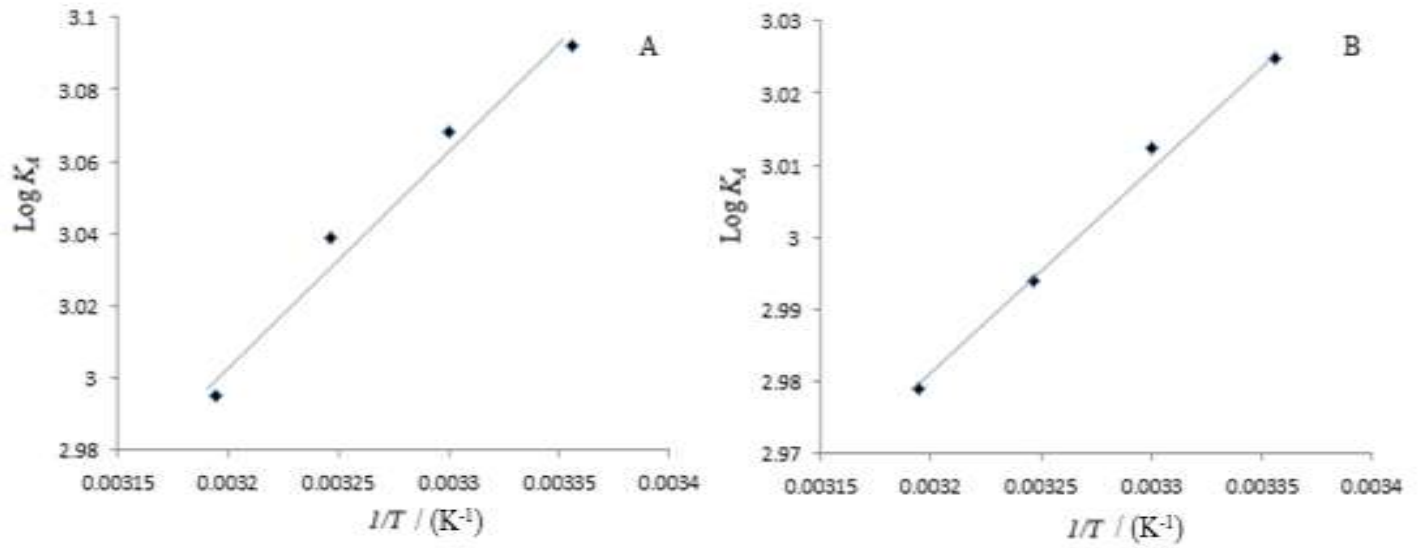

Figure 8-The linear relationship between $\log \mathrm{K}_{\mathrm{A}}$ and $1 / \mathrm{T}\left(\mathrm{K}^{-1}\right)$, for Lys: DHA, A- in water and $\mathrm{B}$ - in $\mathrm{NaCl}$ solutions. 

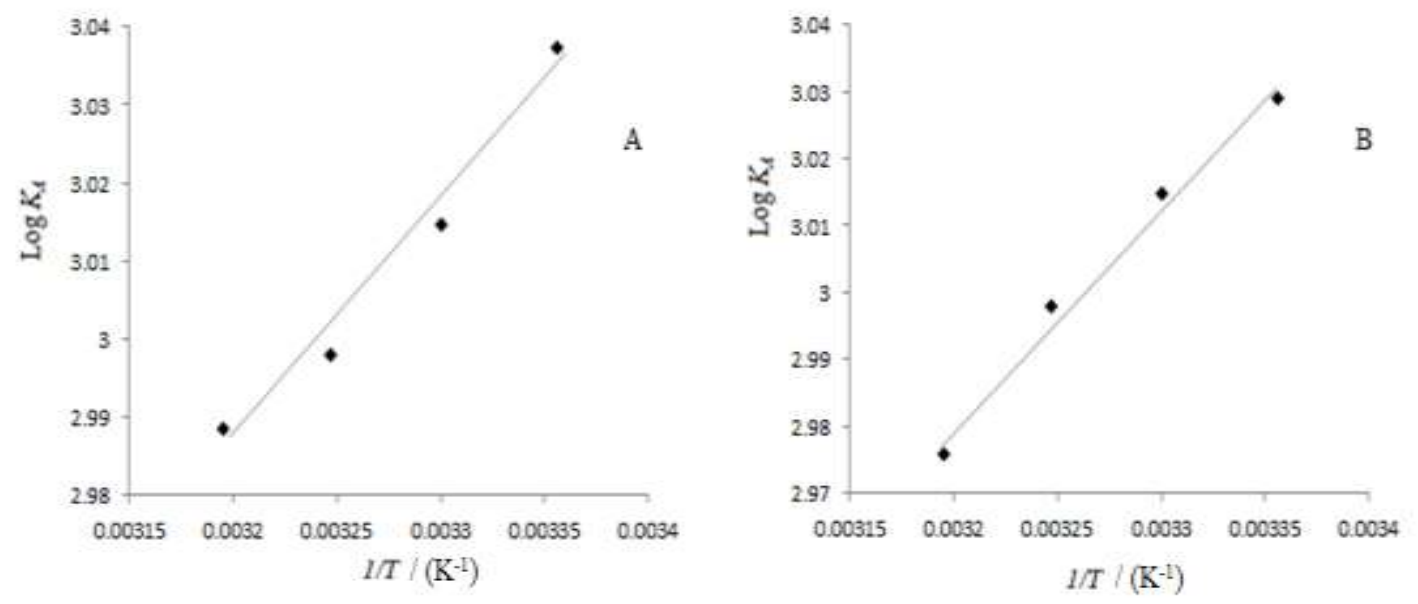

Figure 9-The linear relationship between $\log \mathrm{K}_{\mathrm{A}}$ and 1/T $\left(\mathrm{K}^{-1}\right)$, for $\operatorname{Arg}$ : DHA, A- in water and $\mathrm{B}$ - in $\mathrm{NaCl}$ solutions.

The change in Gibbs free energy $\Delta \mathrm{G}^{\mathrm{o}}\left(\mathrm{KJ} \mathrm{mol}^{-1}\right)$, refers to the usable energy of the association interaction in a solution is obtained from Eq. 13 [28].

$$
\Delta G^{\circ}=-R T \ln K_{A}
$$

Equation-14 [29] is used to evaluation the entropy change, $\Delta \mathrm{S}^{\mathrm{o}}\left(\mathrm{J} \mathrm{K}^{-1} \mathrm{~mol}^{-1}\right)$, as a measure of randomness.

$$
\Delta G^{o}=\Delta H^{\circ}-T \Delta S^{\circ}
$$

Thermodynamic results for $\Delta \mathrm{G}^{\circ}$ and $\Delta \mathrm{S}^{\circ}$, are calculated at $298 \mathrm{~K}$, and the data obtained from equations (11-14) are listed in Table-4.

Table 4-Thermodynamic parameters: $\Delta \mathrm{G}^{\mathrm{o}}\left(\mathrm{kJ} \mathrm{mol}^{-1}\right), \Delta \mathrm{S}^{\mathrm{o}}\left(\mathrm{J} \mathrm{K}^{-1} \mathrm{~mol}^{-1}\right), \Delta \mathrm{H}^{\mathrm{o}}\left(\mathrm{kJ} \mathrm{mol}^{-1}\right)$, and $\Delta \mathrm{E}_{\mathrm{s}}(\mathrm{kJ}$

\begin{tabular}{|c|c|c|c|c|}
\hline DHA & \multicolumn{4}{|c|}{ Thermodynamic parameters } \\
\hline $\mathrm{C} \times 10^{-3} \mathrm{M}$ & $\Delta \mathbf{E}_{3}$ & $\Delta \mathbf{H}^{\circ}$ & $\Delta \mathbf{G}^{0}$ & $\Delta \mathbf{S}^{\circ}$ \\
\hline \multicolumn{5}{|c|}{ Lys $\left(2 \times 10^{-3} \mathrm{M}\right) /$ water } \\
\hline 2 & 05.72 & -12.15 & -17.64 & 18.43 \\
\hline 3 & 07.51 & -14.30 & -19.13 & 16.21 \\
\hline 4 & 10.01 & -21.44 & -19.49 & -06.54 \\
\hline 5 & 13.22 & -25.02 & -20.92 & -13.76 \\
\hline \multicolumn{5}{|c|}{ Lys $\left(2 \times 10^{-3} \mathrm{M}\right) / \mathrm{NaCl}$} \\
\hline 2 & 03.22 & -05.36 & -17.26 & 67.75 \\
\hline 3 & 04.65 & -07.51 & -19.10 & 38.89 \\
\hline 4 & 06.01 & -10.72 & -19.84 & 30.60 \\
\hline 5 & 07.86 & -15.37 & -20.68 & 17.82 \\
\hline \multicolumn{5}{|c|}{$\operatorname{Arg}\left(2 \times 10^{-3} \mathrm{M}\right) /$ water } \\
\hline 2 & 08.93 & -06.01 & -17.33 & 37.99 \\
\hline 3 & 11.44 & -20.37 & -18.79 & -05.30 \\
\hline 4 & 17.15 & -28.59 & -20.00 & -20.83 \\
\hline 5 & 21.44 & -35.74 & -20.75 & -50.30 \\
\hline \multicolumn{5}{|c|}{$\operatorname{Arg}\left(2 \times 10^{-3} \mathrm{M}\right) / \mathrm{NaCl}$} \\
\hline 2 & 04.65 & -06.79 & -17.28 & 35.20 \\
\hline 3 & 05.00 & -07.86 & -18.97 & 37.28 \\
\hline 4 & 07.51 & -12.51 & -19.93 & 24.90 \\
\hline 5 & 07.15 & -12.87 & -20.82 & 26.68 \\
\hline
\end{tabular}
$\mathrm{mol}^{-1}$ ), of different solutions relative to AA concentration.

From Table-4 the results show that: 
The $\Delta \mathrm{E}_{\mathrm{S}}$, appears in most samples a positive value for the association and this refers to a higher mobility and conductivity values of ions in the solutions [28]. The activation energy of the association process in $\mathrm{NaCl}$ solutions has lower values relative to the same solutions in water and this refers to the increase in solubility of amino acids under study.

The values of $\Delta \mathrm{G}^{\mathrm{o}}$, have the tendency to decrease with increase in DHA concentration in water and $\mathrm{NaCl}$ solutions, this refers to a transfer of the free solvent molecules to the bulk solvent [28] and increases in HBs formation related to increase in association constant. $\Delta \mathrm{G}^{\mathrm{o}}$, has negative values, this point to that the association is preferred rather than the dissociation in water and $\mathrm{NaCl}$ solutions.

The $\Delta \mathrm{H}^{\mathrm{o}}$ shows negative values in water and $\mathrm{NaCl}$ solutions, and this refers to exothermic association interaction. $\Delta \mathrm{H}^{\mathrm{o}}$ of the association process in $\mathrm{NaCl}$ solutions increase in values relative to the same solutions in water and this can be connected to raise solubility of amino acids. HBs have a tendency to associate the molecules in the solution so they have fewer random $\left(\Delta S^{\circ}\right)$ as comparative to solution with no hydrogen bonding or lower, and this is seen at increase in DHA concentration in water and $\mathrm{NaCl}$ solutions. While positive values of $\Delta \mathrm{S}^{\mathrm{o}}$, refer to an increase in disorder of ions in solutions [28].

\section{Conclusions}

Ion association of ionizable side chains $\alpha$-amino acids (Lysine and Arginine) in water and in $\mathrm{NaCl}$ solutions are studied. The results refer that the values of $\Lambda^{\circ}$, increase for ion association as the temperature increase, while $\mathrm{K}_{\mathrm{A}}$, values decrease because the viscosity of the solvent is decreased. The dynamic radiuses $(\mathrm{R})$ of the concerned ions increase as diffusion of the ions increases related to change in temperature, and $\mathrm{R}$ of Lys and $\mathrm{Arg}$ in $\mathrm{NaCl}$ solutions have increased in size and decrease in diffusion coefficient and this accustomed to increase AAs solubility as compared with the same solutions in water.

$\Delta \mathrm{H}^{\mathrm{o}}, \Delta \mathrm{G}^{\mathrm{o}}, \Delta \mathrm{S}^{\mathrm{o}}$, and $\Delta \mathrm{E}_{\mathrm{S}}$, also calculated. $\Delta \mathrm{E}_{\mathrm{S}}$, appears in most samples a positive value for the ion association, and the association process in $\mathrm{NaCl}$ solutions has lower values relative to the same solutions in water and this refers to the increase in solubility of amino acids under study.

The values of $\Delta \mathrm{G}^{\mathrm{o}}$, have the tendency to decrease with increase in DHA concentration in water and $\mathrm{NaCl}$ solutions, related to a transfer of the free solvent molecules to the bulk solvent and increase in HBs formation as the increase in association constant. $\Delta \mathrm{G}^{\circ}$, has negative values, this point to that the association process is preferred in water and $\mathrm{NaCl}$ solutions.

The $\Delta \mathrm{H}^{\circ}$ shows an exothermic association interaction in water and $\mathrm{NaCl}$ solutions. $\Delta \mathrm{H}^{\circ}$ of the association process in $\mathrm{NaCl}$ solutions increase in values relative to the same solutions in water and this can be connected to raise solubility of amino acids. HBs have a tendency to associate the molecules in the solution so they have fewer random $\left(\Delta S^{\circ}\right)$ as comparative to solution with no hydrogen bonding or lower, and this is seen at increase in DHA concentration in water and $\mathrm{NaCl}$ solutions.

\section{Acknowledgements}

The author is grateful to chemical industries department stuffs in Institute of technology - Baghdad for our help in this search.

\section{References}

1. Belitz, H. D., Grosch, W. and Schieberle, P. 2009. Amino Acids, Peptides, Proteins. Food Chemistry, 65: 1-34. Doi: 10.1007/978-3-540-69934-7-2.

2. James, M. and May, M.D. 2012. Vitamin C Transport and Its Role in the Central Nervous System. Subcell Biochem, 56: 85-103. Doi:10.1007/978-94-007-2199-9-6.

3. Tsukaguchi, H., Tokui, T., Mackenzie, B., Berger, UV., Chen, XZ., Wang, Y, Brubaker RF. and Hediger, MA. 1999. A Family of Mammalian $\mathrm{Na}^{+}$-Dependent L-Ascorbic Acid Transporters. Nature, 399: 70-75.

4. Wilson, J. X. 2002. The Physiological Role of Dehydroascorbic Acid. FEBS Letters, 527: 5-9.

5. Kaneko, J. Harvey, J. and Bruss, M. 2008. Clinical Biochemistry of Domestic Animals. $6^{\text {th }}$ ed. Elsevier Inc. 712 P.

6. El-Shobaki, FA., El-Hawary, Z., Saleh, N. and Morcos, SR. 1977. Effect of Authentic and Natural Vitamin C and Carotene on Amino Acid Absorption. Z Emahrungswiss, 16(1): 12-7.

7. Testa, B., de Waterbeemd, Hv. and Folkers, G. 2007. Pharmacokinetic Optimization in Drug Research: Biological, Physicochemical, and Computational Strategies. $1^{\text {st }}$ ed. Switzerland. Verlag Helvetica Chimica Acta. 513-524. 
8. Lu, A., Wang, Z., Zhou, Z., Chen, J. and Wang, Q. 2015. Application of "Hydrogen Bonding Interaction" in New Drug Development: Design, Synthesis, Antiviral Activity, and SARs of Thiourea Derivatives. J. Agric. Food Chem., 63: 1378-1384. Doi: 10.1021/jf505355r.

9. Zhai, C., Hou, B., Peng, P., Zhang, P., Li, L. and Chen, X. 2018, Hydrogen Bonding Interaction of Ascorbic Acid with Nicotinamide: Experimental and Theoretical Study, Journal of Molecular Liquids, 249: 9-15.

10. Das, S. and Dash, U.N. 2013. Ion Association of Glycine, $\alpha$-Alanine and $\beta$-Alanine in Water and Water+ D-Glucose Mixtures at Different Temperatures, Journal of Applied Pharmaceutical Science, 3(9): 060-064. Doi: 10.7324/JAPS.2013.3911

11. Iwahara, J., Esadze, A. and Zandarashvili, L. 2015. Physicochemical Properties of Ion Pairs of Biological Macromolecules, Biomolecules, 5: 2435-2463. Doi:10.3390/biom5042435

12. Kadhim, M. J. 2019. Studies on Ion Association of Some $\alpha$-Amino Acids with L-Ascorbic Acid in Aqueous Solution at Different Temperature. Iraqi Journal of Science, 60(1): 1-11.

13. Bert, M. T. and Joni, B. W. 1982. Dehydroascorbic Acid. Advances in chemistry, 200: 101-123.

14. Keys, O. H. 1939. Standardization of 2, 6-Dichlorophenolindophenol for Ascorbic Acid Titration. Ind. Eng. Chem. Anal. Ed., 11(5): 293-293.

15. Yuzlenko, O. and Lazaridis, T. 2011. Interactions between Ionizable Amino Acid Side Chains at a Lipid Bilayer-Water Interface. J Phys Chem B., 115(46): 13674-13684. Doi:10.1021/jp2052213.

16. Gaffney, K. J., Piletic, I. R. and Fayer, M. D. 2002. Hydrogen Bond Breaking and Reformation in Alcohol Oligomers Following Vibrational Relaxation of a Non-Hydrogen-Bond Donating Hydroxyl Stretch. J. Phys. Chem. A, 106: 9428-9435.

17. Malmberg, C.G. and Maryott, A.A. 1956. Dielectric Constant of Water from 0 to 1000 C. Journal of Research of the National Bureau of Standards, 56(I): 1-8.

18. Joseph, K., Mordechai, S. and William, A.W. 1978. Viscosity of Liquid Water in The Range -8 C to 150 C. J. Phys. Chem. Ref. Data, 7(3): 941-948.

19. Boruń1, A. and Bald, A. 2016. Ionic Association and Conductance of Ionic Liquids in Dichloromethane at Temperatures from 278.15 to 303.15 K. Ionics, 22:859-867.

20. Khoshkbarchi, M. K. and Vera, J. H. 1997. Effect of $\mathrm{NaCl}$ and $\mathrm{KCl}$ on the Solubility of Amino Acids in Aqueous Solutions at 298.2 K: Measurements and Modeling. Ind. Eng. Chem. Res., 36(6): 2445-2451. Doi: 10.1021/ie9606395.

21. Mukhopadhyay, A., Nandi, A. and Pal, M. 1994. Ionic Association and Ion-Solvent Interactions: Conductance of N-Ethyl-4-Cyanopyridinium Iodide in Ethanol-Water Mixtures. Indian Journal of Chemistry, 33A: 297-302.

22. Fuoss, R. M. 1978. Paired ions: Dipolar Pairs as Subset of Diffusion Pairs. Proc. Natl. Acad. Sci. USA, 75(1): 16-20.

23. Chenyakin, Y., Ullmann, D. A., Evoy, E., Wolff, L. R., Kamal, S. and Bertram, A. K. 2017. Diffusion Coefficients of Organic Molecules in Sucrose-Water Solutions and Comparison with Stokes-Einstein Predictions. Atmos. Chem. Phys., 17: 2423-2435.

24. Stephen, K. and Howard, D.D. 1996. Evaluation of Diffusion Coefficients of Metallic Ions in Aqueous Solutions. Electrounulysrs, 8(4): 307-313.

25. Lindsay, S.M. 2010. Introduction to Nanoscience. $1^{\text {st }}$ ed. New York. Oxford University Press Inc. $107 \mathrm{P}$.

26. Atkins, P. and de Paula, J. 2006. Atkins Physical Chemistry. $8^{\text {th }}$ ed. New York. W. H. Freeman and Company. 766 P.

27. Yeatts, L. B. and Marshall, W. L. 1971. Electrical Conductance's and Ionization Behavior of Sodium Chloride in Dioxane-Water Solutions at $1000^{\circ}$ and Pressures to 4000 Bars. Journal of Physical Chemistry, 75(8): 1099-1107.

28. El-Hammamy, N., El-Hammamy, M. and Kawana, A. 2014. Thermodynamic Studies of Ion Association of $s$-Acetylthiocholine Halides and Perchlorate in Methanol Solutions. J. Mex. Chem. Soc., 58(1): 11-15.

29. Zheng, J., Kwak, K., Chen, X., Asbury, J. B. and Fayer, M. D. 2006, Formation and Dissociation of Intra-Intermolecular Hydrogen-Bonded Solute-Solvent Complexes: Chemical Exchange TwoDimensional Infrared Vibrational Echo Spectroscopy, J. Am. Chem. Soc., 128: 2977-2987. 